\title{
Development of a New Nanocarrier for Dietary Garcinol: Characterization and In Vitro Efficacy Evaluation Using Breast Cancer Stem Cells Grown in Hypoxia
}

\author{
Amal Charindra Hulangamuwa, ${ }^{1}$ Meran Keshawa Ediriweera, ${ }^{1}$ \\ Umapriyatharshini Rajagopalan, ${ }^{1}$ Desiree Nedra Karunaratne, ${ }^{2}$ \\ Kamani Hemamala Tennekoon, ${ }^{1}$ and Sameera Ranganath Samarakoon ${ }^{1}{ }^{1}$ \\ ${ }^{1}$ Institute of Biochemistry, Molecular Biology and Biotechnology, Cumaratunga Munidasa Mawatha, University of Colombo, \\ Colombo 03, Sri Lanka \\ ${ }^{2}$ Department of Chemistry, Faculty of Science, University of Peradeniya, Kandy, Sri Lanka
}

Correspondence should be addressed to Sameera Ranganath Samarakoon; sam@ibmbb.cmb.ac.lk

Received 8 December 2020; Revised 19 January 2021; Accepted 2 February 2021; Published 10 February 2021

Academic Editor: Luis Patarata

Copyright (c) 2021 Amal Charindra Hulangamuwa et al. This is an open access article distributed under the Creative Commons Attribution License, which permits unrestricted use, distribution, and reproduction in any medium, provided the original work is properly cited.

\begin{abstract}
Garcinol (GA), a polyisoprenylated benzophenone derivative, is one of the major phytochemicals found in a number of fruits of Garcinia. This study aimed to develop a new nanodelivery system comprising GA, hyaluronic acid (HA), and poly(lactic-coglycolic acid) (PLGA) to actively target breast cancer stem cells (bCSCs) grown under hypoxic conditions. HA has been reported to show higher affinity for the cluster-determinant 44 receptor (CD44), while PLGA is an FDA-approved biodegradable polymer used in clinical applications. Nanoparticles (NPs) were prepared by emulsion solvent diffusion technique using DMAB as the emulsifier. Following preparation, particle size, surface charge, and polydispersity index of NPs were characterized. Antiproliferative effects of NPs were assessed by the WST-1 cell proliferation assay. Apoptotic effects of NPs were evaluated by the caspase-3/7 assay. Effects of prepared NPs on the expression of genes related to hypoxia-inducing factors $(H I F-1 \alpha$ and $H I F-2 \alpha)$ and notch ligands (DLL1 and Jagged1) were evaluated using real-time PCR. HA-coated garcinol-loaded NPs (HA-GA-NPs) showed greater antiproliferative effects in bCSCs grown under hypoxia. Moreover, HA-GA-NPs showed an improved cellular uptake via receptor-mediated endocytosis compared to non-HA-coated GA-NPs. Exposure to GA-HA-NPs resulted in a significant downregulation in hypoxia-inducing factors and notch pathway-related genes. Activation of caspase-3/7 confirmed the HA-GA-NPs can induce apoptosis in bCSCs. Overall findings of the study confirm that HA-GA-NPs can be considered as an effective nanodelivery system to target bCSCs grown under the hypoxic microenvironment.
\end{abstract}

\section{Introduction}

The Asian and African regions of the world are rich in wild fruits, among which the family Clusiaceae represents a large number of species with various pharmacological potentials. The genus Garcinia in the family Clusiaceae comprises more than 300 species and fruits of many Garcinia species (Garcinia mangostana, Garcinia cambogia, Garcinia gardneriana, and Garcinia indica) which are commonly consumed worldwide [1]. Consumption of Garcinia fruits has been reported to provide a wide range of benefits to human health. For example, various extracts of Garcinia fruits possess the ability to prevent obesity, reduce blood cholesterol levels, lower appetite, and tune immunity [1]. Toxicological studies demonstrate that Garcinia extracts show no toxic/adverse effects at high daily doses [2]. In a recent study, we showed that the hexane extract of Garcinia quaesita fruits can induce apoptosis in bCSCs [3]. In addition, Garcinia fruit species are phytochemically diverse. Xanthone derivatives, polyisoprenylated benzophenones, 
citric acid derivatives, and terpenes are abundantly found in Garcinia species [4]. Among the phytochemicals from Garcinia, garcinol (GA), a polyisoprenylated benzophenone derivative, is a well-known phytochemical present in high levels in many Garcinia fruit species. GA has been reported to possess several bioactivities such as antimicrobial, antiinflammatory, and antitumorigenic activity [5].

Cancer stem cells (CSCs) are a group of tumor cells that can constantly self-renew and differentiate into functionally heterogeneous cells. A most effective cancer therapy should not only target cancer cells but also specifically target cancer stem cells [6]. Even though the traditional chemotherapy and radiotherapy target most of the fast-growing cancer cells in a tumor, surviving CSCs will lead to the recurrence of the tumor [7]. It is also important to overcome the multidrug resistance of CSCs by addressing the drug efflux by membrane transporters, vesicular exocytosis, and reduced drug uptake [8]. Nanoassisted drug delivery systems have helped to overcome the major limitations in conventional chemotherapy such as poor drug solubility, lack of selectivity, poor bioavailability, and shorter circulation. As a result, nanomedicines reduce the toxicity towards normal tissues and improve the accumulation of the drug in tumors [9].

Hypoxic regions of a tumor experience low nutrient levels and oxygen supply due to poor vasculature [10]. Importantly, hypoxia induces dedifferentiation of cancer cells into CSC phenotype by activating stem genes and upregulates CSC signaling pathways to maintain the stemness [11]. Tumor hypoxia also induces CSCs to express hypoxia-inducible factors (HIFs) leading to the activation of related signaling pathways causing increased tumor growth, enhanced angiogenesis, metastasis, and drug resistance $[11,12]$.

Polymeric nanoparticles range from 10 to $1000 \mathrm{~nm}$ in size, and they are well known for their biocompatibility and biodegradability [13]. Due to their stability in systemic circulation with enhanced half-life, polymeric nanoparticles are considered to be excellent carriers for sustained delivery of drugs [13, 14]. Poly(lactic-co-glycolic acid) (PLGA) is one of the most acknowledged biodegradable polymers approved by the US Food and Drug Authority (FDA) and European Medicines Agency (EMA) for clinical applications [15]. The cluster-determinant 44 receptor (CD44), a cell surface adhesion protein, is one of the most consistently used biomarkers to identify and characterize bCSC phenotype [16]. CD44 receptor has a high affinity for hyaluronic acid (HA) [17]. $\mathrm{HA}$, a negatively charged biocompatible glycosaminoglycan, is an abundant component of the extracellular matrix (Mattheolabakis et al. [18]). Surface-modified PLGA-drug carrier with HA can target and enter cells efficiently via the CD44 receptor-mediated endocytosis pathway $[19,20]$.

So far, no studies have been reported regarding HAcoated polymeric nanodelivery system to target CSCs under hypoxic conditions. In this paper, we report that HA-coated GA-loaded PLGA nanoparticles effectively suppress the activity of bCSCs grown under hypoxia.

\section{Materials and Methods}

2.1. Materials. PLGA (50:50, molecular weight: 30000-60000 Da) was purchased from Sigma-Aldrich (St. Louis, MO, USA, P2191). Didodecyltrimethylammonium bromide (sc-3282-73-3), garcinol (sc-78824-30-3), and hyaluronic acid (sc-337865) were purchased from Santa Cruz Biotechnology, Texas. Growth medium (L-15) was purchased from the American Type Cell Culture, MA, USA. Cancer stem cell medium-Premium ${ }^{\mathrm{TM}}$ (serum-free) was purchased from ProMab Biotechnologies Inc., USA. Ultralow attachment cell culture flasks $\left(25 \mathrm{~cm}^{3}\right.$ and $\left.75 \mathrm{~cm}^{3}\right)$ and plates (24- and 96-well plates) were purchased from Corning Inc. (Corning, NY, USA). MidiMAC separator, bovine serum albumin (BSA) and rinsing solution, LD columns, multistand, LS columns, Plunger, CD24MicroBeads, CD24-anti-MicroBeads, and CD44 MicroBeads were purchased from Miltenyi Biotec, Germany. Oligonucleotide primers were purchased from Integrated DNA Technologies Inc., USA. All other reagents used were of molecular biology grade and purchased from Sigma-Aldrich Corporation, St. Louis, Missouri, USA, unless otherwise specified.

\subsection{Preparation of HA-Coated GA-Loaded Nanoparticles.} Hyaluronic acid-coated garcinol-loaded PLGA nanoparticles (HA-GA-NPs) were prepared by emulsion solvent diffusion technique described by Yang et al. [21] with some modifications. In brief, $22.5 \mathrm{mg}$ of PLGA polymer and $1 \mathrm{mg}$ of garcinol were dissolved in $2.25 \mathrm{~mL}$ ethyl acetate to obtain a $1 \%(\mathrm{w} / \mathrm{v})$ organic phase. The organic phase was added dropwise to $5 \mathrm{~mL}$ of $0.5 \%$ DMAB surfactant solution and then homogenized at $17,500 \mathrm{rpm}$ for 5 minutes. The obtained primary emulsion was then added to $10 \mathrm{~mL}$ of $0.1 \%$ HA solution, and the organic phase was evaporated overnight under magnetic stirring at $550 \mathrm{rpm}$. The excess surfactant was removed by centrifugation at $12,000 \mathrm{rpm}$ for $15 \mathrm{~min}$. The pellet was freeze-dried to get the solid nanoparticle powder. Blank NPs were prepared with PLGL polymer alone. HA-NPs were prepared by coating the blank NPs with HA. GA-NPs were GA-loaded PLGL NPs without HA coating.

2.3. Characterization of Nanoparticles. The nanoparticles were characterized in terms of their particle size, zeta potential, polydispersity index (PDI), encapsulation efficiency (EE), and loading capacity (LC).

2.3.1. Nanoparticle Yield, Encapsulation Efficiency, and Loading Capacity. Encapsulation efficiency of garcinol-encapsulated PLGA nanoparticles was determined using spectrophotometry. The absorbance of garcinol remaining in the supernatant after the centrifugation was measured at $356 \mathrm{~nm}$ using the UV-visible spectrophotometer. A standard calibration plot was generated for a series of pure garcinol $(5-50 \mu \mathrm{g} / \mathrm{mL})$, and the concentration of garcinol remaining in the supernatant was determined using the standard curve. 
Nanoparticle yield, drug loading capacity, and encapsulation efficiency were calculated using the following equations:

$$
\begin{aligned}
& \text { nanoparticle yield }(\%)= \frac{\text { weight of NPs }}{\text { initial weight of the drug and the polymer }} \\
& \times 100, \\
& \text { drug loading }(\%)= \frac{\text { weight of the drug in NPs }}{\text { weight of the NPs }} \times 100, \\
& \text { encapsulation efficiency }(\%)=\frac{\text { weight of the drug in NPs }}{\text { initial weight of the drug }} \times 100 .
\end{aligned}
$$

2.3.2. Particle Size, Polydispersity Index, and Zeta Potential. Mean particle size and polydispersity index (PDI) were measured by dynamic light scattering (DLS) technique. Zeta potential was measured by laser Doppler electrophoresis technique using Malvern Zetasizer nanoinstrument (Malvern Instrument Ltd., Malvern, UK) in triplicate in three independent experiments.

2.4. Cell Culture. Human triple-negative breast cancer cells (MDA-MB-231) were cultured in Leibovitz's L-15 medium supplemented with $10 \%(\mathrm{v} / \mathrm{v})$ fetal bovine serum (FBS) in a humidified incubator with $5 \% \mathrm{CO}_{2}$ at $37^{\circ} \mathrm{C}$.

2.5. Isolation of bCSCs from MDA-MB-231 Cell Line. bCSCs were isolated from MDA-MB-231 cells by magneticactivated cell sorting technique using $\mathrm{CD} 24^{-} / \mathrm{CD} 44^{+}$ MicroBeads. MDA-MB-231 cells were transferred into a sterile $15 \mathrm{~mL}$ centrifuge tube and centrifuged at $300 \mathrm{~g}$ for $10 \mathrm{~min}$ at $4^{\circ} \mathrm{C}$. The pellet was resuspended in $40 \mu \mathrm{L}$ of running buffer. CD24- biotin $(10 \mu \mathrm{L})$ was added to the cell suspension and incubated for $15 \mathrm{~min}$ at $4-8^{\circ} \mathrm{C}$. Cells were washed with $1 \mathrm{~mL}$ of running buffer followed by centrifugation at $300 \mathrm{~g}$ for $10 \mathrm{~min}$ at $4^{\circ} \mathrm{C}$. The pellet was resuspended in $80 \mu \mathrm{L}$ of running buffer, and $20 \mu \mathrm{L}$ of anti-biotin MicroBeads was added. The cell suspension was then mixed and incubated for $15 \mathrm{~min}$ at $4-8^{\circ} \mathrm{C}$. Cells were washed with $1.2 \mathrm{~mL}$ running buffer and centrifuged at $300 \mathrm{~g}$ for $10 \mathrm{~min}$ at $4^{\circ} \mathrm{C}$ followed by resuspension of the pellet in $50 \mu \mathrm{L}$ running buffer. The cell suspension was then added to the LD column after mixing with $1 \mathrm{~mL}$ of running buffer. Unlabeled CD24 ${ }^{-}$ cells were depleted from the LD column, and the flowthrough was collected. The collected flowthrough was centrifuged at $300 \mathrm{~g}$ for $10 \mathrm{~min}$ at $4^{\circ} \mathrm{C}$ followed by resuspension of the pellet in $80 \mu \mathrm{L}$ of running buffer. $\mathrm{CD} 44^{+}$ MicroBeads $(20 \mu \mathrm{L})$ were then added, mixed, and incubated for $15 \mathrm{~min}$ at $2-8^{\circ} \mathrm{C}$. Cells were mixed with $1-2 \mathrm{~mL}$ running buffer and centrifuged at $300 \mathrm{~g}$ for $10 \mathrm{~min}$ at $4^{\circ} \mathrm{C}$ followed by resuspension of the pellet in $500 \mu \mathrm{L}$ running buffer. Obtained cell suspension was poured into the LS column, and unlabeled flowthrough was collected and discarded. LS column was removed from the magnetic stand and immediately flushed out with $5 \mathrm{~mL}$ of running buffer using a plunger. Collected CD $24^{-} / \mathrm{CD} 44^{+}$cancer stem cell populations were centrifuged (at $300 \mathrm{~g}$ for $10 \mathrm{~min}$ at $4^{\circ} \mathrm{C}$ ) and resuspended in $2 \mathrm{~mL}$ of the CSC premium medium. Cells were counted using a hemocytometer, and approximately $2.5 \times 10^{5}$ cells $/ \mathrm{mL}$ were mixed with $5 \mathrm{~mL}$ of the serum-free CSC premium medium and cultured in ultralow flasks (at $37^{\circ} \mathrm{C}$ in $5 \% \mathrm{CO}_{2}$ and $95 \%$ air humidity). bCSCs were maintained as mammospheres suspended in the cancer stem premium medium in ultralow flasks.

2.6. Maintaining bCSCs under Hypoxic Conditions. Ultralow flasks with breast CSCs were incubated in a modular incubator hypoxic chamber. A Petri dish with $10-20 \mathrm{~mL}$ of sterile water was placed inside the chamber to humidify and prevent excessive evaporation of the culture medium. The chamber was purged at a rate of 20 liters $/ \mathrm{min}$ for $4 \mathrm{~min}$ using a gas mixture containing 5\% oxygen, $5 \%$ carbon dioxide, and $90 \%$ nitrogen to provide a hypoxic environment. After purging, the gas cylinder was disconnected and sealed with clamps, and the chamber was incubated at $37^{\circ} \mathrm{C}$.

2.7. WST-1 Cell Proliferation Assay. Breast CSCs were cultured in ultralow 96-well plates $\left(5 \times 10^{3}\right.$ cells $)$ and incubated for 3 days under hypoxia. Cells were treated with a series of concentrations $(1.625,3.5,7.5,15$, and $30 \mu \mathrm{g} / \mathrm{mL})$ of paclitaxel (positive control), pure garcinol, blank NPs (negative control), garcinol-loaded NPs (GA-NPs), and HA-coated garcinol-loaded NPs (HA-GA-NPs). The plates were incubated for $48 \mathrm{~h}$ in hypoxia, and after the incubation, initial absorbance was taken at $440 \mathrm{~nm}$ and $640 \mathrm{~nm}$ using the microplate reader. Then, cells were treated with $20 \mu \mathrm{L}$ of WST-1 reagent, and the plates were incubated at $37^{\circ} \mathrm{C}$ for 4 $5 \mathrm{~h}$ in $95 \%$ air humidity and $5 \% \mathrm{CO}_{2}$. After the incubation, the plates were shaken for $1 \mathrm{~min}$ to mix the contents, and the absorbance was taken at $440 \mathrm{~nm}$ and $640 \mathrm{~nm}$. The percentage of cell viability was calculated as a percentage of control values using the following equation, and $\mathrm{IC}_{50}$ was calculated using GraphPad Prism software (GraphPad Software Inc., San Diego, CA, USA).

2.8. Morphological Changes. An inverted phase contrast microscope (Olympus CKX41, Japan) was used to observe morphological changes of bCSCs grown under hypoxia after exposure to different concentrations of paclitaxel (positive control), pure garcinol, blank NPs (negative control), GANPs, and HA-GA-NPs.

2.9. Real-Time PCR (RT-PCR). Breast CSCs $\left(1.5 \times 10^{6}\right)$ were seeded in nonadherent plates (6 wells) and grown under hypoxia for $72 \mathrm{~h}$. After incubation, cells were treated with HA-GA-NPs $(0.125$ and $0.250 \mu \mathrm{g} / \mathrm{mL})$ and further incubated for $48 \mathrm{~h}$ under hypoxic conditions. Following incubation, cells were washed with PBS, and RNA was extracted using TRIzol reagent. Complementary DNA (c-DNA) was then synthesized using extracted RNA. RT-PCR was performed in the Stratagene Mx3000P instrument using MESA Green qPCR Master Mix Plus for SYBR Assay (Eurogentec, Seraing, Liège, Belgium). Primers used in this study were selected from a study conducted by Xing et al. [22] (Table 1). 
Table 1: Primers used in real-time PCR experiments.

\begin{tabular}{lc}
\hline Primers & Oligonucleotide sequences \\
\hline \multirow{2}{*}{ GAPDH } & F $5^{\prime}$-TGGCATTGCCCTCAACGACCAC-3' \\
& R $5^{\prime}$-ACATGACAAGGTGCGGCTCCCTA-3' \\
HIF-1 $\alpha$ & F $5^{\prime}$-CATAAAGTCTGCAACATGGAAGGT-3' \\
& R $5^{\prime}$-ATTTGATGGGTGAGGAATGGGTT-3' \\
HIF-2 $\alpha$ & F $5^{\prime}$-GCGCTAGACTCCGAGAACAT-3' \\
& R $5^{\prime}$-TGGCCACTTACTACCTGACCCTT-3' \\
Jagged 1 & F $5^{\prime}$-TCGCTGTATCTGTCCACCTG-3' \\
& R $5^{\prime}$-AGTCACTGGCACGGTTGTAG- $3^{\prime}$ \\
DLL1 & F $5^{\prime}$-CAGGGTTGCACATTTCTCC-3 ${ }^{\prime}$ \\
& R $5^{\prime}$-GCACGGACCTCAAGTACTCC-3' \\
\hline
\end{tabular}

2.10. Statistical Analysis. GraphPad Prism software was used for statistical analysis in the present study. One-way analysis of variance (ANOVA) with Bonfferoni's posttest was used for group comparisons. $P$ values $<0.05$ were considered statistically significant. The experiments were repeated with three biological and technical replicates.

\section{Results and Discussion}

3.1. Preparation and Optimization of Nanoparticles. Blank NPs were used to optimize variable parameters. Effects of homogenization speed, organic to aqueous phase volume ratio, and surfactant concentration on the characteristics of blank NPs are summarized in Table 2 after four individual experiments.

According to the optimized conditions, 1\% DMAB concentration, a homogenization speed of $17,500 \mathrm{rpm}$, and $1: 4$ organic to aqueous phase volume ratio were chosen as optimum conditions to prepare drug-loaded NPs. Blank NPs, HA-NPs, GA-NPs, and HA-GA-NPs were prepared, and particle size, PDI, and zeta potential were characterized. Surface modification of NPs by HA was carried out via electrostatic attractions. Information on nanoparticle characterization is summarized in Table 3.

Encapsulation efficiency shows the percentage of a drug that is successfully entrapped into nanoparticles. The amount of garcinol encapsulated was determined by measuring absorbance using a UV-Vis spectrophotometer after three individual preparations. A standard calibration curve was plotted with varying garcinol concentrations $\left(R^{2}=0.99\right)$, and concentration of garcinol in the NP supernatant after the first centrifugation step was calculated. Encapsulation efficiency, loading capacity, and nanoparticle yield of drugloaded NPs are summarized in Table 4.

3.2. Determination of bCSC Proliferation under Normoxic and Hypoxic Conditions. Hypoxia was induced in a hypoxic chamber with $5 \%$ oxygen in comparison to $21 \%$ oxygen level in normoxia. bCSCs were seeded (5000 cells/well) in 96-well plates and grown under both normoxic and hypoxic conditions. Cell proliferation was determined using the WST-1 assay on the $4^{\text {th }}, 5^{\text {th }}$, and $6^{\text {th }}$ days upon the initial seeding. It was evident that hypoxia stimulated the rate of proliferation in bCSCs in comparison to the cells grown under normoxia. From day 4 to 6 , hypoxia showed a rapid cell proliferation compared to the normoxia. On $4^{\text {th }}, 5^{\text {th }}$, and $6^{\text {th }}$ days, bCSCs showed 2.0-, 2.5-, and 3.8-fold proliferations, respectively, under normoxia. On the same days, bCSCs grown under hypoxia showed 4.0-, 8.9-, and 11.3-fold proliferations, respectively (Figure 1).

3.3. Morphological Features of bCSCs Treated with Pure Garcinol, Blank-NPs, GA-NPs, GA-HA-NPs, and Paclitaxel. Morphological features of bCSCs after exposure to pure GA, GA-NPs, HA-GA-NPs, and paclitaxel (positive control) are shown in Figure 2. Cell shrinking and a dose-dependent reduction in the formation of tumor spheres were observed after treatments. GA-HA-NPs showed more inhibitory effects on the growth of bCSCs over pure garcinol and GANPs (Figure 2).

3.4. Antiproliferative Effects of Pure Garcinol, GA-NPs, HAGA-NPs, Blank NPs, HA-NPs, and Paclitaxel in bCSCs. Antiproliferative effects of pure garcinol, GA-NPs, HA-GANPs, blank NPs, HA-NPs, and paclitaxel in bCSCs were evaluated at 24,48 , and $72 \mathrm{~h}$ incubation by the WST-1 cell proliferation assay. Both dose- and time-dependent cell growth inhibitions were observed for free drug (garcinol) and drug-encapsulated NPs. IC $_{50}$ values of prepared NPs and the free drug are shown in Table 5. Of the tested treatments, GA-HA-NPs and GA-NP showed higher antiproliferative effects in bCSCs at 24,48 , and $72 \mathrm{~h}$ incubation periods (Table 5). Moreover, HA-GA-NPs showed the highest antiproliferative effects among all the tested treatments.

3.5. Expression of HIF1 $\alpha, H I F 2 \alpha, D L L 1$, and Jagged 1 Genes under Hypoxic and Normoxic Conditions. Relative mRNA expressions of hypoxia-related genes (HIF $1 \alpha$ and HIF2 $\alpha$ ) and notch pathway-related genes (DLL1 and Jagged1) were examined under both hypoxic and normoxic conditions. Real-time PCR evaluation demonstrated that hypoxia can increase the expression of HIF $1 \alpha$, HIF $2 \alpha$, DLL1, and Jagged 1 genes over normoxia in bCSCs (Figure 3 ).

3.6. Expression of HIF1 $\alpha, H I F 2 \alpha, D L L 1$, and Jagged1 upon Treatment with HA-GA-NPs. The relative mRNA expressions of HIF $1 \alpha, \mathrm{HIF} 2 \alpha$, DLL1, and Jagged 1 genes were investigated in HA-GA-NP-treated bCSCs. GAPDH was used as the housekeeping gene. HIF $1 \alpha$ mediates the adaptive response of cancer cells to the changes in oxygen concentrations through transcriptional activation of downstream genes. On the contrary, HIF $2 \alpha$ enhances the tumor-initiating cell population. DLL1 and Jagged 1 are two of the five ligands present in the notch signaling pathway. DLL1 governs cell fate decisions and cell-to-cell communication, whereas Jagged1 is involved in enhanced angiogenesis of tumors.

A significant downregulation $(p<0.0001)$ was observed in the mRNA expression of HIF $1 \alpha$ and HIF $2 \alpha$ at both doses (1.93- and 1.25-fold changes for HIF $1 \alpha$ and 4.74- and 2.47fold changes for HIF $2 \alpha$ at 0.125 and $0.250 \mu \mathrm{g} / \mathrm{mL}$ doses, 
TABLE 2: Effects of variables (DMAB concentration, organic to aqueous phase volume ratio, and homogenization speed) on NP characteristics.

\begin{tabular}{lcccc}
\hline Parameters & Trial 1 & Trial 2 & Trial 3 & Trial 4 \\
\hline DMAB concentration $(\mathrm{mg} / \mathrm{mL})(\%)$ & 1 & 1 & 0.5 & 1 \\
Organic to aqueous phase volume ratio & $1: 2$ & $1: 4$ & $1: 4$ & $1: 4$ \\
Homogenization speed (rpm) & 17,500 & 17,500 & 17,500 & 13,500 \\
Particle size $(\mathrm{nm})$ & $127.6 \pm 0.3$ & $110.6 \pm 1.2$ & $151.9 \pm 1.7$ & $124.2 \pm 0.7$ \\
PDI & $0.072 \pm 0.003$ & $0.086 \pm 0.01$ & $0.047 \pm 0.01$ & $0.102 \pm 0.003$ \\
Zeta potential $(\mathrm{mV})$ & $36.67 \pm 0.9$ & $39.63 \pm 0.5$ & $36.67 \pm 0.9$ & $38.67 \pm 1.2$ \\
\hline
\end{tabular}

TABLE 3: Characterization of NPs.

\begin{tabular}{lccc}
\hline Type of NPs & Size $(\mathrm{nm})$ & PDI & Zeta potential $(\mathrm{mV})$ \\
\hline Blank NP & $121.1 \pm 1.1$ & $0.086 \pm 0.01$ & $41.8 \pm 1.1$ \\
HA-NP & $147.3 \pm 0.8$ & $0.131 \pm 0.02$ & $56.4 \pm 6.7$ \\
GA-NP & $151.6 \pm 0.8$ & $0.116 \pm 0.02$ & $37.1 \pm 0.6$ \\
GA-HA-NP & $158.8 \pm 7.4$ & $0.192 \pm 0.01$ & $47.4 \pm 0.8$ \\
\hline
\end{tabular}

TABLE 4: Drug loading capacity, encapsulation efficiency, and yield of NPs.

\begin{tabular}{lcc}
\hline Parameters & GA-NP & GA-HA-NP \\
\hline Drug loading (DL, \%) & 5.3 & 5.02 \\
Encapsulation efficiency (EE, \%) & 65.8 & 60.31 \\
NP yield (\%) & 41.6 & 31.74 \\
\hline
\end{tabular}

respectively (Figure 4(a))). DLL1 was also significantly $(p<0.0001)$ downregulated resulting in 2.27- and 4.20-fold changes at 0.125 and $0.250 \mu \mathrm{g} / \mathrm{mL}$ concentrations, respectively. Jagged1 expression had the similar pattern of downregulation showing 1.49- and 3.18-fold changes at 0.125 and $0.250 \mu \mathrm{g} / \mathrm{mL}$ concentrations, respectively (Figure 4(b)).

3.7. Caspase-3/7 Expression. According to results obtained in the caspase assay, caspase-3/7 activity was increased at both doses $(0.125 \mu \mathrm{g} / \mathrm{mL}$ and $0.250 \mu \mathrm{g} / \mathrm{mL})$ tested. However, a significant $(p<0.0082)$ increase in caspase-3/7 activity was observed only at the highest dose tested (Figure 5).

\section{Discussion}

The main aim of this investigation was to prepare GA-loaded PLGA-NPs coated with HA and to target bCSCs grown under hypoxic conditions. The lack of solubility of GA in the aqueous medium has been identified to limit its pharmacokinetic profile, bioavailability, and therapeutic efficacy [23]. This necessitated the development of an effective delivery system which can enhance the bioavailability and therapeutic efficacy of GA. The nanoformulation is used to overcome this problem, and nanoparticle-based therapies have gained much attention as anticancer therapies in recent years. Research on nanoformulations has been reported to improve bioavailability and pharmacokinetic profile of a number of natural drugs which show poor solubility in the aqueous medium [24]. The selection of a suitable polymer for nanoformulation is critical as it determines the overall

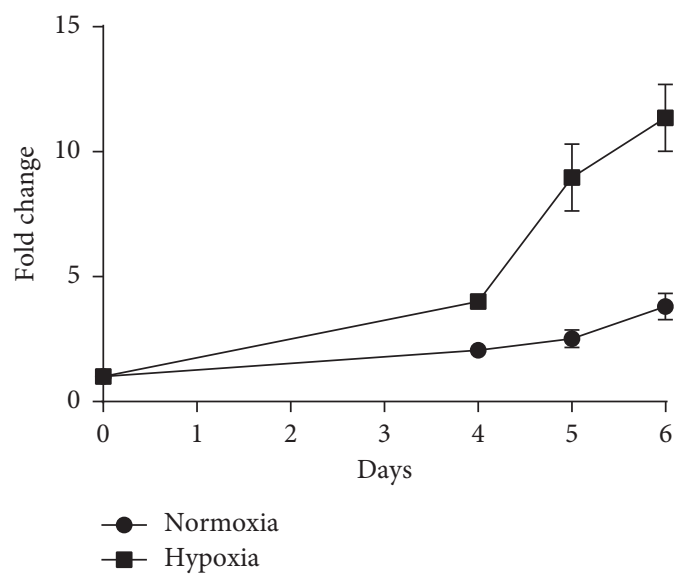

FIgURE 1: Growth rate (fold changes) of bCSCs maintained under normoxic and hypoxic conditions.

properties (stability, bioavailability, and solubility) of the nanoformulation. Poly(lactic-co-glycolic acid) (PLGA) is an FDA-approved biocompatible polymer. PLGA breaks down into lactic acid and glycolic acid upon degradation and is eliminated from the body through the Krebs cycle [25]. Emulsion solvent diffusion technique was used to prepare NPs in the present study as this method is comparatively simple to perform and has produced quality PLGA-NPs [26].

Studies have reported the antiproliferative effects of GA in several cancer cell lines. Pan et al. [27] reported that GA can induce apoptosis in human leukaemia HL-60 cells. A study conducted by Ahmad et al. [28] demonstrated that GA induces apoptosis through downregulation of the NF-kB signaling pathway in breast cancer cells. A recent study demonstrates that GA can exert anticancer effects through suppression of p300 and TGF- $\beta 1$ signaling [29]. Another recent study reports antineoplastic effects of GA in gastric cancer cells through targeting the PI3K/AKT signaling pathway [30]. GA has also been reported to inhibit the nicotine-induced MDA-MB-231 breast cancer cell proliferation through downregulation of the nicotinic receptor and cyclin D3 proteins [31]. Gaonkar et al. [23] prepared first GA-loaded polymeric NPs and demonstrated cytotoxic effects in B16F10 (skin), HepG2 (liver), HCT-116 (colon), and KB-oral cancer cell lines. Wang et al. reported that GA downregulates CSC-like biomarker ALDH1A1 in non-small cell lung cancer. So far, no studies have been carried out to assess the anticancer effects of GA in bCSCs. 

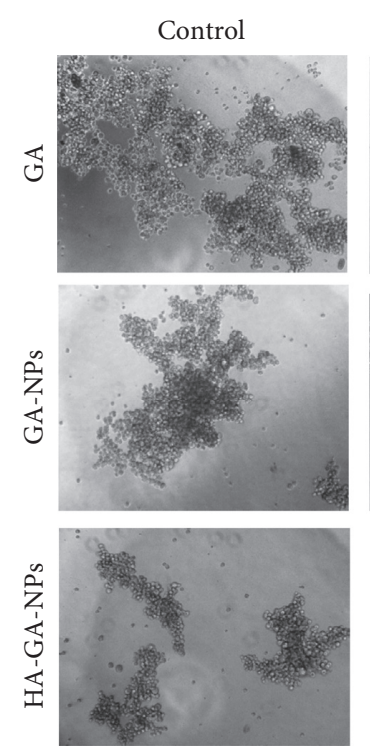

Control

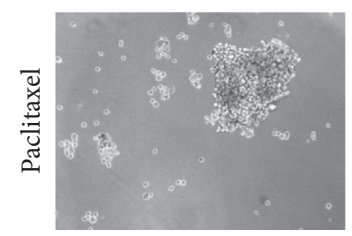

$3.125 \mu \mathrm{g} / \mathrm{mL}$
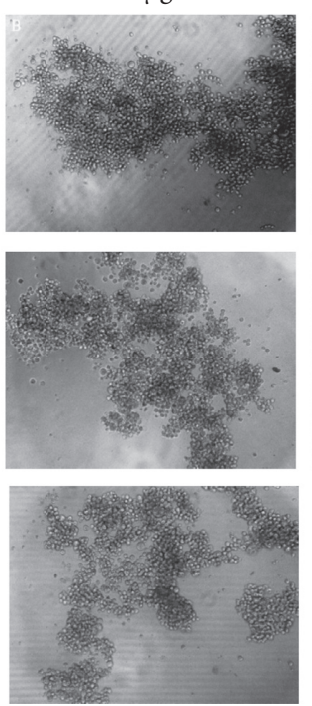

$1.25 \mu \mathrm{g} / \mathrm{mL}$

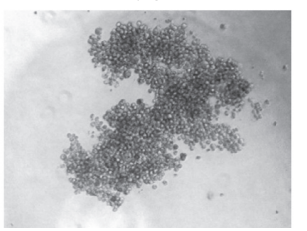

$6.25 \mu \mathrm{g} / \mathrm{mL}$
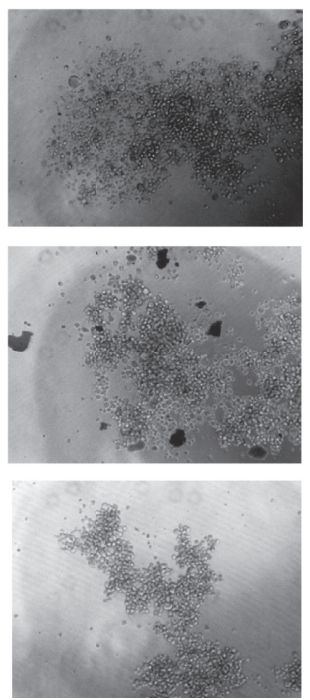

$2.5 \mu \mathrm{g} / \mathrm{mL}$

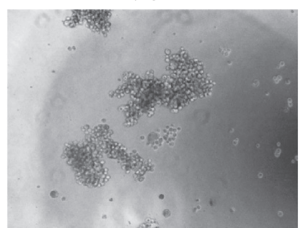

$12.5 \mu \mathrm{g} / \mathrm{mL}$
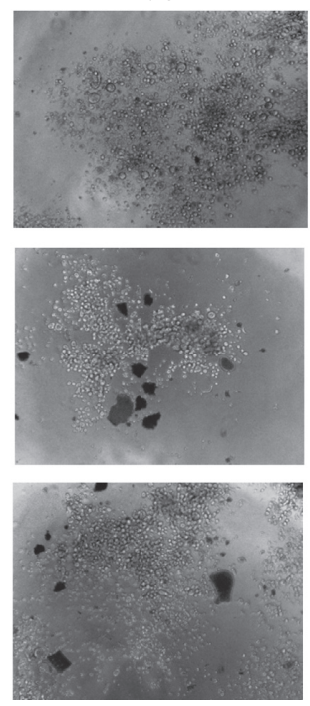

$5 \mu \mathrm{g} / \mathrm{mL}$

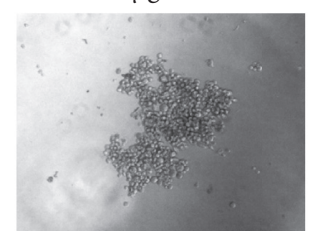

$25 \mu \mathrm{g} / \mathrm{mL}$
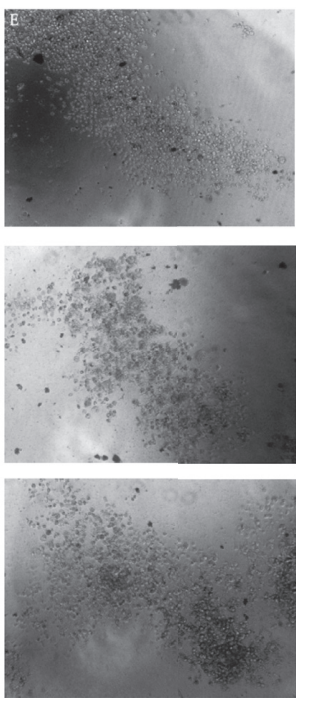

$10 \mu \mathrm{g} / \mathrm{mL}$

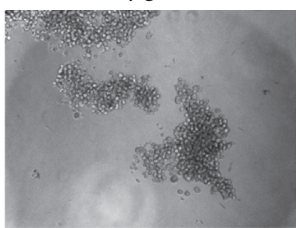

FIgURe 2: Morphological changes in bCSCs incubated with GA, GA-NPs, HA-GA-NPs, and paclitaxel for 24h (magnification: 100x).

TABle 5: $\mathrm{IC}_{50}$ value of each NP assessed at 24, 48, and $72 \mathrm{~h}$ incubations.

\begin{tabular}{lccc}
\hline \multirow{2}{*}{ Drug/NP } & \multicolumn{3}{c}{$\mathrm{IC}_{50}(\mu \mathrm{g} / \mathrm{mL})$} \\
& $24 \mathrm{~h}$ & $48 \mathrm{~h}$ & $72 \mathrm{~h}$ \\
\hline Garcinol & 21.16 & 17.06 & 10.22 \\
PTX & 49.74 & 31.85 & 20.87 \\
GA-NP & 10.23 & 6.049 & 1.701 \\
HA-GA-NP & 5.54 & 4.03 & 0.81 \\
\hline
\end{tabular}

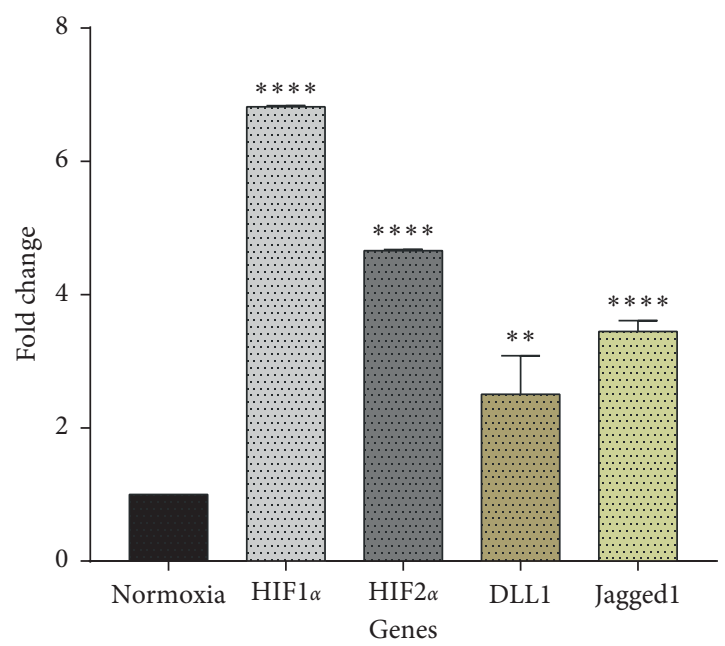

FIgURE 3: Comparison of the expression of genes (HIF $1 \alpha$, HIF $2 \alpha$, DLL1, and Jagged1) under normoxic and hypoxic conditions $\left({ }^{* * * *} p<0.0001 ;{ }^{* *} p<0.0073\right)$.
Particle size is the key parameter in nanoparticle formulation. The enhanced permeation and retention effect (EPR) allow NPs (less than $500 \mathrm{~nm}$ ) to penetrate into tumors [32]. Larger NPs are more likely to be removed by phagocytosis [33]. In this study, emulsion solvent diffusion method produced GA-loaded NPs approximately of $150 \mathrm{~nm}$ in size, which is big enough to escape renal clearance and small enough to enter into the tumors by EPR effect. Also, this size is ideal to be administered intravenously and to render the plasma half-life longer [34]. Dynamic light scattering technique was used to measure the PDI which ranges the NP size distribution in a colloidal suspension in a scale of $0-1$, where the values closer to zero indicate the homogeneity of the suspension and the values closer to 1 indicate a broad size distribution [35]. PDI value less than 0.4 is reported to be desirable for polymer NPs to achieve the EPR effect [36]. Increased homogenization speed resulted in a lower PDI value, and drug-loaded polymer NPs recorded the lowest PDI value of $0.116 \pm 0.02$ and the highest value of $0.192 \pm 0.01$.

Surfactant concentration plays an important role in determining the particle properties of nanoformulations. DMAB is a cationic stabilizer which produces small and highly stable nanoparticles. Its surface positive charges help to reduce nanoparticle agglomeration [37]. When the DMAB concentration is increased from 0.5 to $1 \mathrm{mg} / \mathrm{mL}$, particle diameter was reduced from $151.9 \mathrm{~nm}$ to $110.6 \mathrm{~nm}$. Surfactant on the droplet surface reduces the interfacial tension between two surfaces, thereby reducing the particle size at higher concentrations [37]. Zeta potential also 


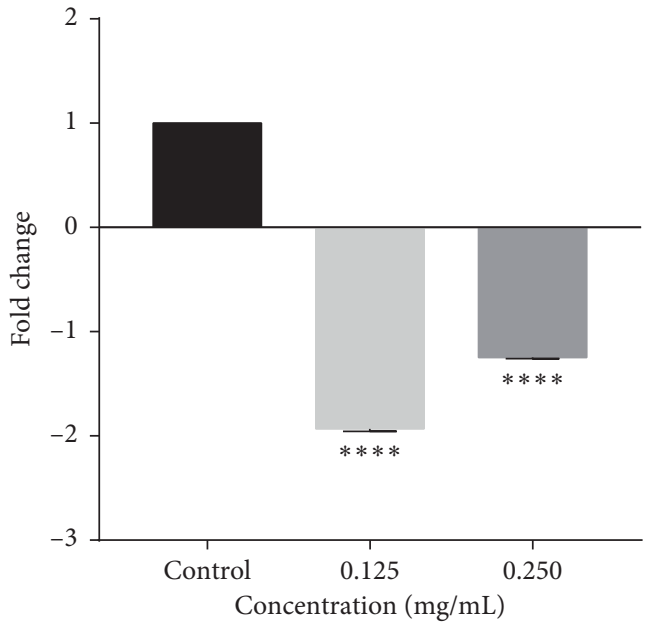

(A)

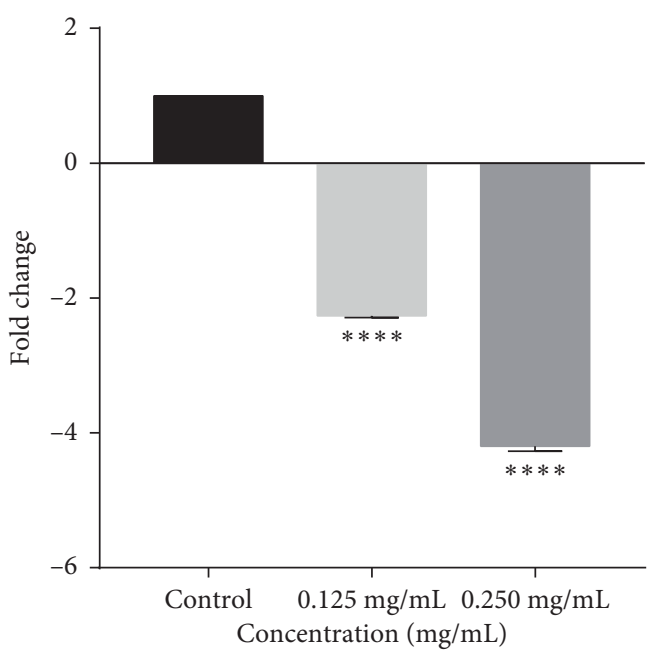

(C)

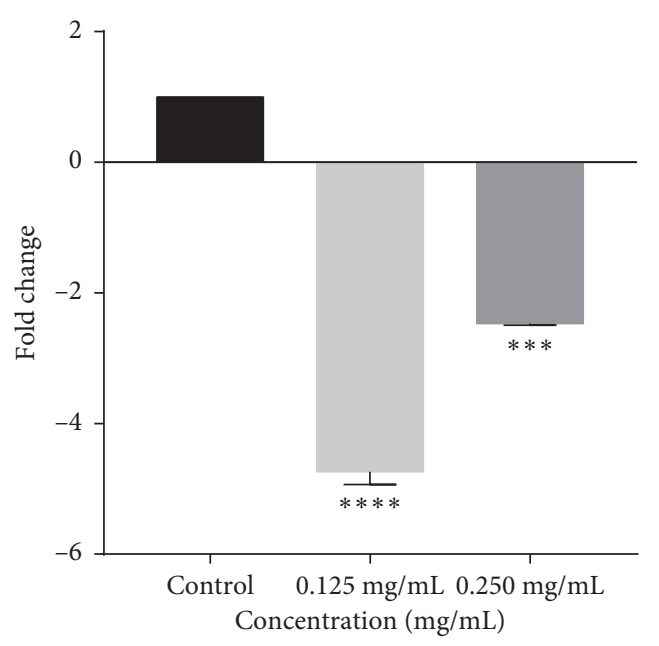

(B)

(a)

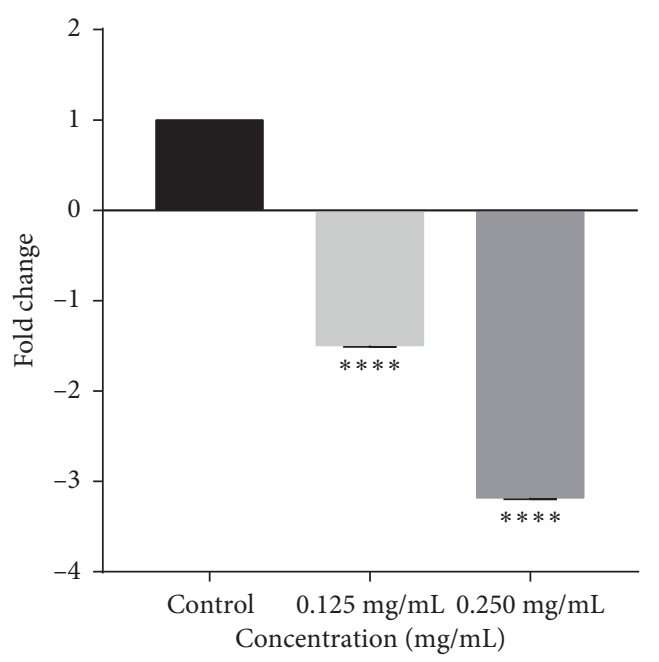

(D)

(b)

Figure 4: (a) Expressions of hypoxia-related genes ((A) HIF- $1 \alpha$ and (B) HIF-2 $\alpha$ ) illustrated as fold changes in HA-GA-NP-treated bCSCs. ${ }^{* * * *} P<0.0001$ compared with the untreated controls. (b) Expressions of notch pathway-related genes ((C) DLL1 and (D) Jagged1) illustrated as fold changes in HA-GA-NP-treated bCSCs. ${ }^{* * *} P<0.0001$ compared with the untreated controls.

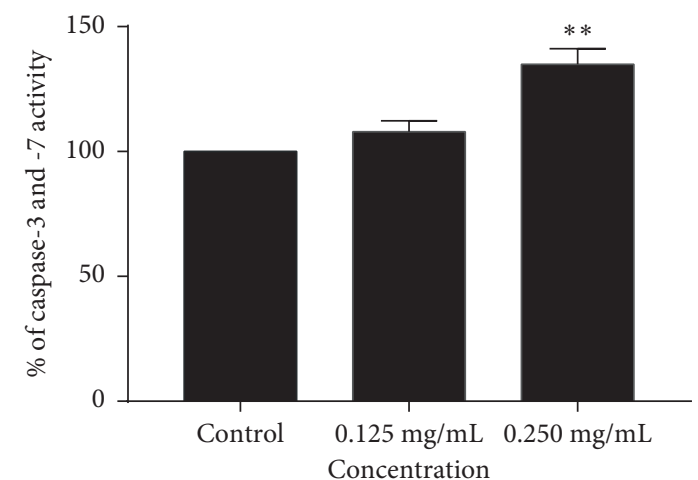

Figure 5: Caspase-3/7 activation in HA-GA-NP-treated bCSCs at $48 \mathrm{~h}$ after incubation $(p<0.0082)$. increased from $+36.67 \mathrm{mV}$ to $+41.83 \mathrm{mV}$ due to increased concentration of the surfactant. When the organic to aqueous phase volume ratio is $1: 2$, it resulted in an average particle diameter of $127 \mathrm{~nm}$ with $36.67 \mathrm{mV}$ zeta potential, whereas $1: 4$ organic to aqueous phase volume ratio resulted in a reduced particle diameter of $110.6 \mathrm{~nm}$ with an increased zeta potential of $39.63 \mathrm{mV}$. Increased organic phase volume increases the viscosity. High viscous resistance of the liquid phase reduces the shear force acting on the emulsion globules. Therefore, $1: 2$ organic to aqueous phase volume ratio produced larger nanoparticles in this study.

Lower homogenization speed $(13,500 \mathrm{rpm})$ resulted in large nanoparticles $(124 \mathrm{~nm})$, while higher homogenization speed $(17,500 \mathrm{rpm})$ resulted in smaller nanoparticles $(110 \mathrm{~nm})$. High-speed emulsification transfers a large 
amount of energy causing a rapid dispersion which eventually reduces the size of emulsion globules [38]. Therefore, $1 \%$ DMAB concentration, $17,500 \mathrm{rpm}$ speed of homogenization, and $1: 4$ organic to aqueous phase volume ratio were chosen as optimum conditions to prepare drug-loaded NPs. Among a few organic solvents, ethyl acetate was chosen as the organic phase to dissolve both the polymer and the drug due to its partial hydrophilic nature [39]. This quality of ethyl acetate lowers the interfacial tension between both organic and aqueous layers to facilitate an easier diffusion [33].

$\mathrm{HA}$ is an anionic polysaccharide found in the extracellular matrix made of glucuronic acid and N-acetyl-Dglucosamine [40]. bCSCs have been reported to possess higher levels of cell surface marker CD44 [41]. The specific affinity of $\mathrm{HA}$ to $\mathrm{CD} 44$ cell surface marker makes $\mathrm{HA}$ a potential moiety to target CD-44 overexpressing bCSCs [42]. HA-coated NPs were prepared by adding the primary emulsion of ethyl acetate containing GA and PLGA into $0.1 \%$ of HA solution under mild stirring. Surface conjugation occurs between PLGA NPs and negatively charged HA molecules via electrostatic interactions [43]. Increasing HA concentration up to $0.2 \%$ resulted in NP agglomeration, producing higher PDI as well as particle size. This is reported to be due to the hydrophilic nature of macromolecular HA, which results in high level of viscosity at higher concentrations [21]. Therefore, $0.1 \%$ HA concentration was chosen as the optimal concentration to decorate the NP surface. Average particle size of HA-GA-NP was found to be $158.8 \pm 7.4 \mathrm{~nm}$ which is slightly higher than that of GA-NPs.

According to the results of the WST-1 proliferation assay, pure GA, GA-NPs, and GA-HA-NPs exhibited both dose- and time-dependent antiproliferative effects. As shown in Table 5, $\mathrm{IC}_{50}$ values of pure GA were much higher than for GA-NPs and GA-HA-NPs at $24 \mathrm{~h}, 48 \mathrm{~h}$, and $72 \mathrm{~h}$ incubations. GA-HA-NPs showed the highest antiproliferative effects among all the treatments at $24 \mathrm{~h}, 48 \mathrm{~h}$, and $72 \mathrm{~h}$ incubations. Blank-NPs or HA-NPs did not suppress cell proliferation at lower doses from 3.125 to $12.5 \mu \mathrm{g} /$ $\mathrm{mL}$. However, a reduction in cell viability was observed at the doses above $25 \mu \mathrm{g} / \mathrm{mL}$, indicating that the PLGA polymer matrix and emulsifier were nontoxic at lower doses. Realtime PCR results indicated that hypoxia significantly increases $(p<0.0001 ; p<0.0073)$ the relative gene expression of both hypoxia-related genes (HIF $1 \alpha$ and HIF $2 \alpha$ ) and notch pathway-related genes (DLL1 and Jagged1) compared to the cells grown under normoxia (Figure 3). HIF1 $\alpha$ is a key mediator of the oxygen-sensing signaling mechanism in cells. The upregulation of HIF $1 \alpha$ and HIF $2 \alpha$ level shows the adaptive response of bCSCs to hypoxic environment.

A significant downregulation $(p<0.0001)$ of HIF $1 \alpha$, HIF2 $\alpha$, DLL1, and Jagged1 was observed in bCSCs treated with GA-HA-NPs at both doses tested $(0.125$ and $0.250 \mu \mathrm{g} /$ $\mathrm{mL}, 48 \mathrm{~h}$ ), suggesting a suppression of the regulation of genes related to hypoxia (HIF $1 \alpha$ and HIF $2 \alpha$ ) with concomitant downregulation of DLL1 and Jagged 1 genes in the notch signaling pathway. However, both HIF $1 \alpha$ and HIF $2 \alpha$ downregulation values were not consistent with their dosages. This may be due to the induction of regenerative or inflammatory response by cellular necrosis at the higher dose as the overall gene expression is a combination of several factors, including the gene expression of drug-treated dying cells, survival responses, and normal responses in living cells [44]. Moreover, increased caspase-3/7 activity was observed at both doses $(0.125 \mu \mathrm{g} / \mathrm{mL}$ and $0.250 \mu \mathrm{g} / \mathrm{mL})$ tested, indicating that HA-GA-NPs can induce caspasedependent apoptosis in bCSCs.

\section{Conclusion}

In conclusion, an efficient HA-coated PLGA-based nanocarrier for GA was developed to target bCSCs grown under the hypoxic conditions. GA-HA-NP induced apoptosis, suppressed bCSC proliferation, and significantly downregulated the expression of notch signaling pathway genes DLL1 and Jagged1.

\section{Data Availability}

The data (results) used to support the findings of this study are included within the article.

\section{Conflicts of Interest}

The authors declare that they have no conflicts of interest.

\section{Authors' Contributions}

SRS conceptualized the study. ACH, MKE, and UR developed methodology and contributed to data analysis. SRS, DNK, and KHT supervised the study. ACH, MKE, SRS, KHT, and DNK reviewed and edited the article.

\section{Acknowledgments}

The financial support provided by the Institute of Biochemistry, Molecular Biology and Biotechnology (IBMBB), University of Colombo, the National Research Council (Grant no. NRC-14-067), and the National Science Foundation of Sri Lanka (Grant no. NSF/RPHS/2016/C-07) is gratefully acknowledged.

\section{References}

[1] M. Hemshekhar, K. Sunitha, M. S. Santhosh et al., "An overview on genus Garcinia: phytochemical and therapeutical aspects," Phytochemistry Reviews, vol. 10, no. 3, pp. 325-351, 2011.

[2] R. B. Semwal, D. K. Semwal, I. Vermaak, and A. Viljoen, "A comprehensive scientific overview of Garcinia cambogia," Fitoterapia, vol. 102, pp. 134-148, 2015.

[3] V. Colamba Pathiranage, J. N. Lowe, U. Rajagopalan et al., "Hexane extract of Garcinia quaesita fruits induces apoptosis in breast cancer stem cells isolated from triple negative breast cancer cell line MDA-MB-231," Nutrition and Cancer, vol. 1, pp. 1-11, 2020.

[4] N. K. Hassan, M. Taher, and D. Susanti, "Phytochemical constituents and pharmacological properties of Garcinia xanthochymus-a review," Biomedicine \& Pharmacotherapy, vol. 106, pp. 1378-1389, 2018.

[5] F. Yamaguchi, T. Ariga, Y. Yoshimura, and H. Nakazawa, "Antioxidative and anti-glycation activity of garcinol from 
Garcinia indica fruit rind," Journal of Agricultural and Food Chemistry, vol. 48, no. 2, pp. 180-185, 2000.

[6] S. Shen, J. X. Xia, and J. Wang, "Nanomedicine-mediated cancer stem cell therapy," Biomaterials, vol. 74, pp. 1-8, 2016.

[7] D. Peer, J. M. Karp, S. Hong, O. C. Farokhzad, R. Margalit, and R. Langer, "Nanocarriers as an emerging platform for cancer therapy," Nature Nanotechnology, vol. 2, no. 12, pp. 751-760, 2007.

[8] J. Mollenhauer, A. Knoop, M. Bak et al., "Breast cancer stem cells: a moving target for cancer nanomedicine," Eur $J$ Nanomed, vol. 4, no. 2-4, pp. 59-72, 2012.

[9] Y. Nakamura, A. Mochida, P. L. Choyke, and H. Kobayashi, "Nanodrug delivery: is the enhanced permeability and retention effect sufficient for curing cancer?" Bioconjugate Chemistry, vol. 27, no. 10, pp. 2225-2238, 2016.

[10] B. Muz, P. de la Puente, F. Azab, and A. K. Azab, "The role of hypoxia in cancer progression, angiogenesis, metastasis, and resistance to therapy," Hypoxia, vol. 3, p. 83, 2015.

[11] A. Carnero and M. Lleonart, "The hypoxic microenvironment: a determinant of cancer stem cell evolution," Bioessays, vol. 1, no. 2, pp. 96-105, 2016.

[12] E. T. Oh, C. W. Kim, S. J. Kim, J. S. Lee, S. S. Hong, and H. J. Park, "Docetaxel induced-JNK2/PHD1 signaling pathway increases degradation of HIF- $1 \alpha$ and causes cancer cell death under hypoxia," Scientific Reports, vol. 6, no. 1, pp. 1-5, 2016.

[13] W. B. Liechty, D. R. Kryscio, B. V. Slaughter, and N. A. Peppas, "Polymers for drug delivery systems," Annual Review of Chemical and Biomolecular Engineering, vol. 1, pp. 149-173, 2010.

[14] S. Sadat, V. Jahan, and A. Haddadi, "Effects of size and surface charge of polymeric nanoparticles on in vitro and in vivo applications," Journal of Biomaterials and Nanobiotechnology, vol. 7, no. 2, p. 91, 2016.

[15] F. F. D. Beça, P. Chourasiya, R. Pandey et al., "Polymeric nanoparticles containing diazepam: preparation, optimization, characterization, in-vitro drug release and release kinetic study," Journal of Clinical Pathology, vol. 3, no. 1, pp. 1-7, 2016.

[16] L. de Beça, J. Caetano, L. Y. Gerhard et al., "Cancer stem cells markers CD44, CD24 and ALDH1 in breast cancer special histological types," Frontiers in Pharmacology, vol. 66, no. 3, pp. 187-191, 2013.

[17] G. He, L. Gu, A. Lim, M. M. Yuan, and J. Mo, "Nanomedicinemediated therapies to target breast cancer stem cells," Journal of Drug Targeting, vol. 7, p. 313, 2016.

[18] M. Mattheolabakis, L. Milane, A. Singh, and M. M. Amiji, "Hyaluronic acid targeting of CD44 for cancer therapy: from receptor biology to nanomedicine," Nature Reviews Cancer, vol. 23, no. 7-8, pp. 605-618, 2015.

[19] G. Zöller, "CD44: can a cancer-initiating cell profit from an abundantly expressed molecule?" Journal of Drug Targeting, vol. 11, no. 4, pp. 254-267, 2011.

[20] X.-Y. Mattheolabakis, Y.-X. Milane, M. Singh, and L. Amiji, "Hyaluronic acid targeting of CD44 for cancer therapy: from receptor biology to nanomedicine," Cancer Letters, vol. 23, no. 7-8, pp. 605-345, 2015.

[21] X. Y. Yang, Y. X. Li, M. Li, L. Zhang, L. X. Feng, and N. Zhang, "Hyaluronic acid-coated nanostructured lipid carriers for targeting paclitaxel to cancer," Cancer Letters, vol. 334, no. 2, pp. 338-345, 2013.

[22] R. H. Xing, S. Okuda, S. Watabe et al., "Hypoxia-induced Jagged 2 promotes breast cancer metastasis and self-renewal of cancer stem-like cells," Scientific Reports, vol. 30, no. 39, pp. 4075-4086, 2011.
[23] C. D. U. Gaonkar, S. R. Ganguly, D. N. Dewanjee et al., "Garcinol loaded vitamin E TPGS emulsified PLGA nanoparticles: preparation, physicochemical characterization, in vitro and in vivo studies," Tropical Journal of Pharmaceutical Research, vol. 7, no. 1, pp. 1-4, 2017.

[24] F. Nwokwu, E. Samarakoon, J. M. Karunaratne et al., "Induction of apoptosis in response to improved gedunin by liposomal nano-encapsulation in human non-small-cell lung cancer (NCI-H292) cell line," Journal of Controlled Release, vol. 16, no. 9, pp. 2079-2087, 2017.

[25] E. Danhier, H. Ansorena, J. M. Silva, R. Coco, A. Le Breton, and V. Préat, "Recent trends in preparation of poly (lactideco-glycolide) nanoparticles by mixing polymeric organic solution with antisolvent," Journal of Nanomaterials, vol. 161, no. 2, pp. 1-522, 2012.

[26] M.-H. Sah and W.-L. Sah, "Induction of apoptosis by garcinol and curcumin through cytochromecrelease and activation of caspases in human leukemia HL-60 cells," Journal of Agricultural and Food Chemistry, vol. 2015, 2015.

[27] M. H. Pan, W. L. Chang, S. Y. Lin-Shiau, C. T. Ho, and J. K. Lin, "Induction of apoptosis by garcinol and curcumin through cytochrome $\mathrm{c}$ release and activation of caspases in human leukemia HL-60 cells," Journal of Agricultural and Food Chemistry, vol. 49, no. 3, pp. 1464-1474, 2001.

[28] J. Ahmad, M. Wang, D. Ali et al., "Garcinol inhibits esophageal cancer metastasis by suppressing the p300 and TGF- $\beta 1$ signaling pathways," Acta Pharmacologica Sinica, vol. 109, no. 6, pp. 1134-1141, 2010.

[29] Y. Wang, C. Wu, X. Zheng et al., "Garcinol inhibits esophageal cancer metastasis by suppressing the p300 and TGF- $\beta 1$ signaling pathways," Oncology Letters, vol. 41, no. 1, pp. 82-92, 2020.

[30] C.-S. Zheng, C.-H. Guo, C.-D. Zhang et al., "Garcinol acts as an antineoplastic agent in human gastric cancer by inhibiting the PI3K/AKT signaling pathway," Breast Cancer Research and Treatment, vol. 20, no. 1, pp. 667-676, 2020.

[31] C. S. Chen, C. H. Lee, C. D. Hsieh et al., "Nicotine-induced human breast cancer cell proliferation attenuated by garcinol through down-regulation of the nicotinic receptor and cyclin D3 proteins," Breast Cancer Research and Treatment, vol. 125, no. 1, pp. 73-87, 2011.

[32] E. Li, R. Tao, S. Zhang et al., "The studies of PLGA nanoparticles loading atorvastatin calcium for oral administration in vitro and in vivo," Colloids and Surfaces B: Biointerfaces, vol. 12, no. 3, pp. 285-291, 2017.

[33] E. Muntimadugu, R. Kumar, S. Saladi, T. A. Rafeeqi, and W. Khan, "CD44 targeted chemotherapy for co-eradication of breast cancer stem cells and cancer cells using polymeric nanoparticles of salinomycin and paclitaxel," Colloids and Surfaces B: Biointerfaces, vol. 143, pp. 532-546, 2016.

[34] B. B. S. Greish, "Enhanced permeability and retention effect for selective targeting of anticancer nanomedicine: are we there yet?" Materials Science and Engineering: C, vol. 9, no. 2, pp. e161-6, 2012.

[35] B. B. Cerqueira, A. Lasham, A. N. Shelling, and R. Al-Kassas, "Development of biodegradable PLGA nanoparticles surface engineered with hyaluronic acid for targeted delivery of paclitaxel to triple negative breast cancer cells," Materials Science and Engineering: C, vol. 76, pp. 593-600, 2017.

[36] V. Alexis, D. D. Pridgen, S. C. Molnar, and M. Farokhzad, "Factors affecting the clearance and biodistribution of polymeric nanoparticles," Pharmaceutical Research, vol. 5, no. 4, pp. 505-515, 2008. 
[37] A. Bhardwaj, N. Ankola, R. Gupta, M. Schneider, C. M. Lehr, and M. R. Kumar, "PLGA nanoparticles stabilized with cationic surfactant: safety studies and application in oral delivery of paclitaxel to treat chemical-induced breast cancer in rat," BioMed Research International, vol. 26, no. 11, pp. 1-2503, 2009.

[38] C. E. Sharma, C. M. Jain, and R. Sareen, "Nanocarriers for diagnosis and targeting of breast cancer," Journal of Biomaterials Science, Polymer Edition, vol. 2013, Article ID 960821, 10 pages, 2013.

[39] S. Astete and A. Sabliov, "Synthesis and characterization of PLGA nanoparticles," Clinical Breast Cancer, vol. 17, no. 3, pp. 247-289, 2006.

[40] C. Yang, X. Wang, X. Yao, Y. Zhang, W. Wu, and X. Jiang, "Hyaluronic acid nanogels with enzyme-sensitive crosslinking group for drug delivery," Journal of Controlled Release, vol. 205, pp. 206-217, 2015.

[41] K. Y. Gangopadhyay, K. H. Nandy, H. Y. Hor et al., "Breast cancer stem cells: a novel therapeutic target," Clinical breast cancer, vol. 13, no. 1, pp. 7-15, 2013.

[42] S. Choi, B. Min, G. Yoon et al., "PEGylation of hyaluronic acid nanoparticles improves tumor targetability in vivo," $D A R U$ Journal of Pharmaceutical Sciences, vol. 21, no. 7, pp. 18801889, 2011.

[43] M. R. Manoochehri, T. R. Darvishi, G. Kamalinia et al., "Surface modification of PLGA nanoparticles via human serum albumin conjugation for controlled delivery of docetaxel," Toxicological Sciences, vol. 21, no. 1, p. 58, 2013.

[44] M. R. Fielden and T. R. Zacharewski, "Challenges and limitations of gene expression profiling in mechanistic and predictive toxicology," Toxicological Sciences, vol. 60, no. 1, pp. 6-10, 2001. 